\title{
Errors and Corrections in Mathematics Literature
}

\author{
Joseph F. Grcar
}

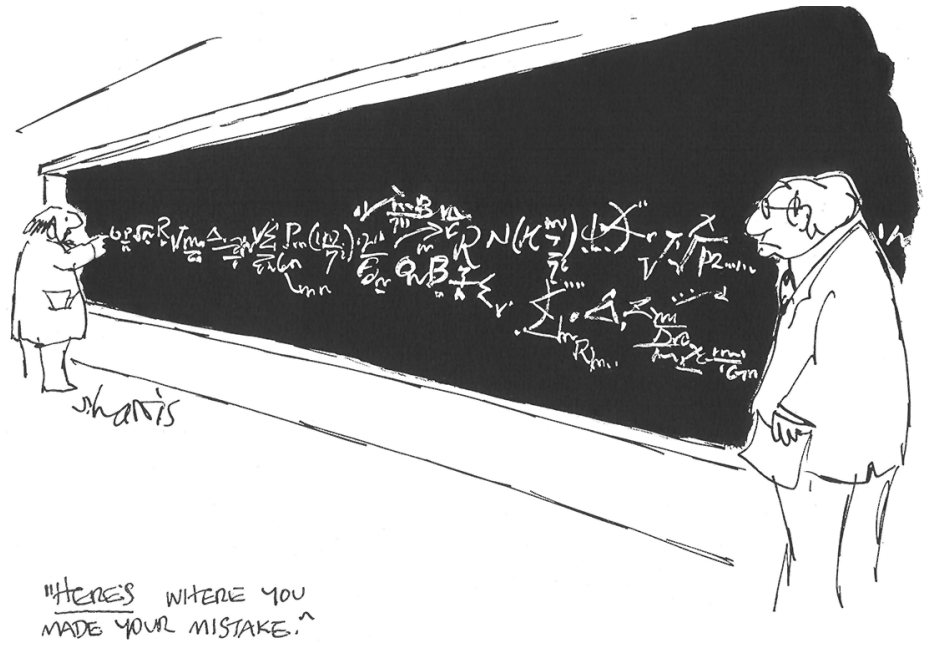

Figure 1. Better late than never.

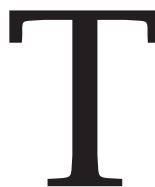

he veracity of scientific research has become a topic of public discussion recently [1]. This article examines why mathematicians correct errors at a slower pace than many other researchers (see Figure 1). Some sociological aspects of mathematics research may make mathematicians averse to publishing corrections, while mathematics journals have comparatively weak procedures to assure the correctness of the literature.

\section{Types of Corrections}

Corrective material appears so infrequently in mathematics that readers may not be familiar with the terminology. The titles of corrective articles can indicate whether errors are corrected or merely found and by whom.

1. "Errata" and "corrigenda" are used mostly interchangeably for corrections of all kinds. A distinction (which is not implied by the Latin words) is sometimes drawn between mistakes

Joseph F. Grcar's email address is jfgrcar@gmai 1 . com. DOI: http://dx.doi.org/10.1090/noti988
Table 1. Some examples of corrections.

1a. Erratum for typographical errors. Note the occasional practice of including names of authors for the corrected paper in the title of the correction. title: Errata to: "The distribution of values of $L\left(1, \chi_{d}\right)$ ", by A. Granville and K. Soundararajan in GAFA 13:5 (2003)"

in: $\quad$ Geom. Funct. Anal. 14(1):245-246, 2004 (Zbl 1188.11039)

1b. Errata for substantive errors. Note different styles of titling in the same journal.

title: A correction to "Bases of the contact-order filtration of derivations of Coxeter arrangements"

in: $\quad$ Proc. Amer. Math. Soc. 136(7):2639, 2008 (Zbl 1141.32011)

title: Erratum to "A finitely presented group with unbounded dead-end depth"

in: Proc. Amer. Math. Soc. 136(7):2641- 2645, 2008 (Zbl 1142.20309)

1c. Addendum.

title: Addendum to "Semistable sheaves in positive characteristic"

in: Ann. Math. (2), 160(3):1211-1213, 2005 (Zbl 1080.14015)

2. Comments and replies.

title: Comments on "State estimation for linear systems with state equality constraints"

in: $\quad$ Automatica 46(11):1929-1932, 2010 (Zbl 1218.93091)

title: Authors' reply to "Comments on 'State estimation for linear systems with state equality constraints'”

in: $\quad$ Automatica 46(11):1933, 2010

(Zbl 1218.93093)

3. Other (disproving a conjecture).

title: On the "Section Conjecture" in anabelian geometry

in: J. Reine Angew. Math 588:221-235, 2005 (Zbl 1108.14021)

made by publishers and those made by authors, as in Nature. "Addenda" are further explanations. Strictly speaking, addenda do not correct errors, although they do perform a corrective function. The corrections for other than publishers' errors are supplied by authors, perhaps upon prompting from readers. 
2. Errors reported by readers appear in a class of short articles with titles that begin with a formulaic "comment on", and conversely there may be a "reply to". These are substantive contributions that undergo special forms of peer review. ${ }^{1}$ Comments do not always challenge articles and may corroborate them.

3. More difficult to identify are a range of other corrective articles that disprove conjectures and rule out directions of enquiry. These corrective publications (1-3) are illustrated in Table 1.

Completing the lexicon are (4) "republications" due to major printing errors and (5) "retractions" due to disastrous mistakes or misbehavior. Retractions can be partial or full and voluntary or forced. Editors may lose sleep over retractions, but they are so rare that it is misleading to dwell on them.

Publication rates for corrections vary widely across disciplines (see Figure 2). The highest rates of (1-2) corrections are in multidisciplinary journals, core physics, and biomedical fields. For the most part, (1) errata correct boilerplate (author and sponsor data), typos, and substantive errors, with the result that many of the substantive errors are found through (2) reader comments, which are especially rare in mathematics. Other corrections (3) may signify intellectual ferment in that, for example, earth science includes climatology.

Because corrections (1-2) appear less frequently in engineering and mathematics than in many subjects, at least one alternative must be true: these fields have lower error rates or lower correction publishing rates. There is no reason to think engineers and mathematicians make mistakes less often than other researchers, while there is some evidence that the research cultures of these fields discourage publishing corrections. ${ }^{2}$ These matters are considered for mathematics: (a) proclivity to error, (b) aversion to acknowledging errors, and (c) weak editorial practice, from which follow some recommendations to improve the correcting process.

\section{Proclivity for Errors}

Mistakes are subjective because they have different impacts, whether in evidence or in conclusions, and because they are relative to a standard of rigor. Mathematics is held to many standards in its capacity as the prototypical "meta-discipline". Moreover, the core literature has some unique systemic possibilities for error.

\footnotetext{
${ }^{1}$ For example, authors of a paper receiving comment do not participate in reviewing the comment. Sometimes comments are misidentified as letters to the editor. Strictly construed, letters express opinions and thus are not reviewed.

${ }^{2}$ Regarding engineering, corrections may be less important (the subject matter changes rapidly) and may have no venue (many articles appear in conference proceedings).
}

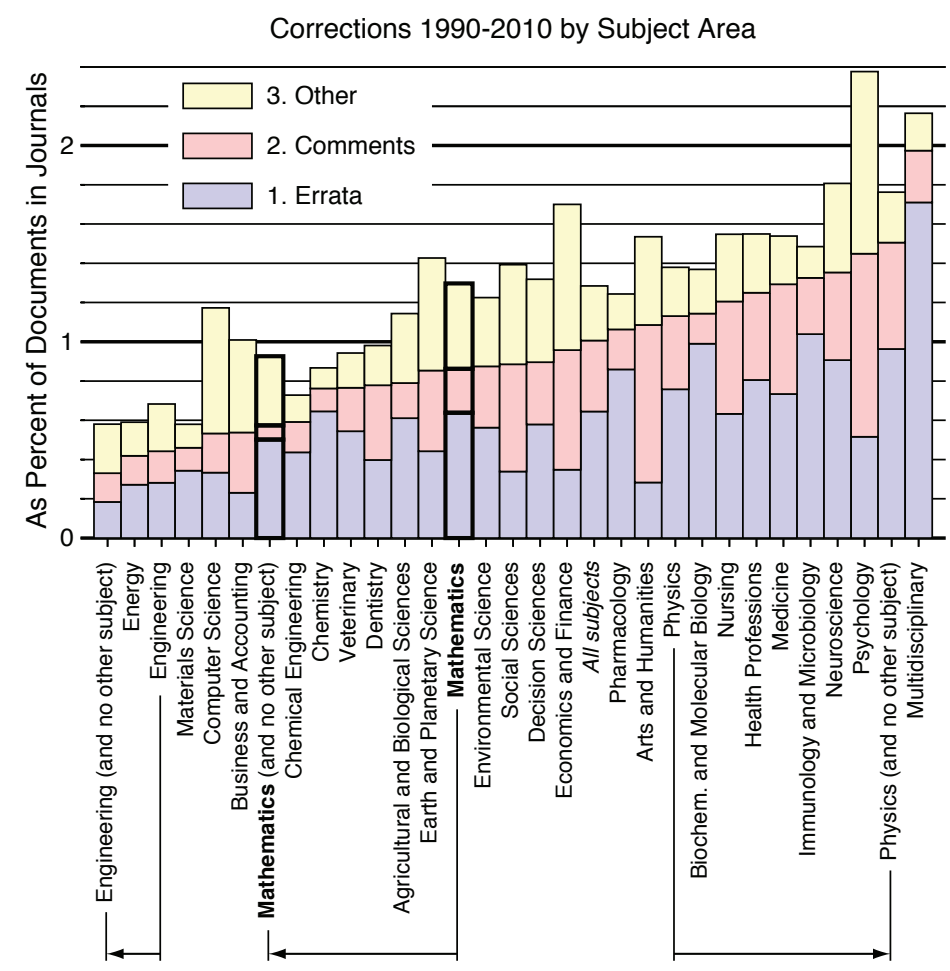

Figure 2. Corrections as percent of journal documents for subject areas of Scopus [2]. Three areas are shown both inclusive and exclusive of interdisciplinary work. Comments are undercounted for journals that choose to identify them as "letters".

Mathematics literature has been shared with other disciplines ever since the "scientific revolution" of the European Renaissance culminated in mathematics becoming the language of scientific theory, as epitomized by Isaac Newton [3]. ${ }^{3}$ Another leg of science was mathematized when statistical methods were created to interpret experimental error [5]. Scientific computation joined the group of interdisciplinary topics in the twentieth century [6]. All this work receives Mathematical Subject Classifications [7] over 60 and comprises slightly over half of mathematics articles for 1990-2010 [8]. The interdisciplinary fraction is probably larger (see Table 2) because 03 logic and 11 number theory have become interdisciplinary from their importance to computer science and information security.

Errors in other fields must be considered for comparison and to encompass interdisciplinary mathematics. Briefly, scientific research draws confirmation from three sources: theory, simulation, and primarily experiment. Discrepancies are seen as paths to discovery [9], [10], with the

\footnotetext{
${ }^{3}$ Recent scholarship on mathematics and Renaissance science is summarized in [4].
} 
Table 2. Percent of mathematics articles shared with any other Scopus subject area (top) and the seven largest intersection partners (bottom). Data for 1990-2010.

\begin{tabular}{|l|r|}
\hline \multicolumn{1}{|c|}{ Other Field } & \% \\
\hline \hline All Others & 58 \\
\hline Computer Science & 20 \\
Physics & 19 \\
Engineering & 16 \\
Decision Sciences & 11 \\
Biochemistry & 7 \\
Medicine & 5 \\
Social Sciences & 3 \\
\hline
\end{tabular}

result that research tends to be "normative" [11] in reconciling evidence (see Figure 3). The trifecta of evidentiary sources heightens confidence in scientific conclusions and permits scientific theory to employ its own standards of rigor for mathematics. Philosophical studies have gone beyond "marveling at the applicability of mathematics to nature in general" [12] to examine scientific argumentation [13]. The highest, or "mathematical", rigor is regarded as an obstacle to investigation [14]. ${ }^{4}$ The issue of appropriate rigor cannot be excised from a discussion of mathematics by restricting the literature, because interdisciplinary mathematics largely develops in the allied fields [18], as, for example, the analysis of algorithms.

The mathematics that is exclusive of interdisciplinary work is unique among the subjects in Figure 2 for being incapable of corroboration. Inspiration may have many sources [19], [20], but evidence consists solely of tautological argument or "proof". This approach developed in the nineteenth century. ${ }^{5}$ Despite concerns about natural language paradox in the twentieth century, no alternative has been accepted:

The main hope of a justification of classical mathematics being gone, most mathematicians decided to use that system anyway...[This history] constitutes the best caution against taking the immovable rigor of mathematics too much for granted.

$$
\text { - John von Neumann [22] }
$$

Variations in rigor (or in philosophies thereof) are not viewed as errors in core mathematics, because, as in the sciences, evidence is distinct

\footnotetext{
${ }^{4}$ Quinn [15, p. 36] observes that many interdisciplinary researchers are "several generations removed" from core mathematics "and some are actually hostile to core methodology." For rigor in quantum theory see [12], [14], and in engineering see [16], [17].

${ }^{5}$ Perspectives on origins and ramifications of using proofs as evidence are given by [15], [21].
}

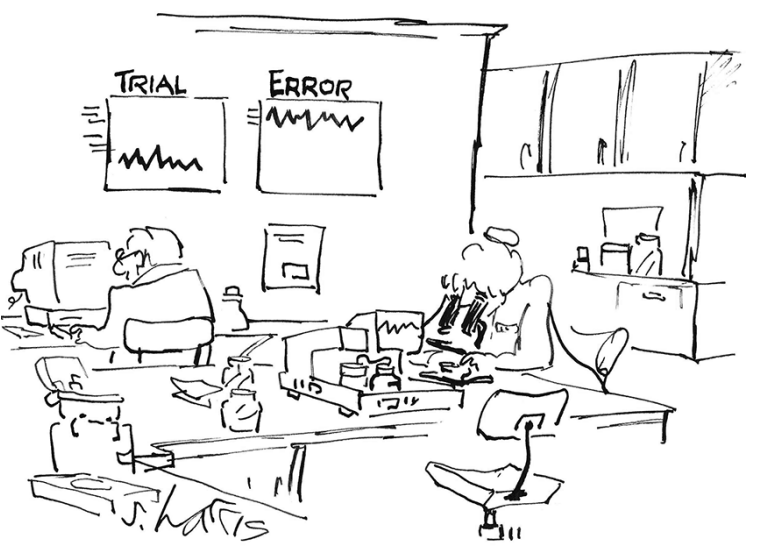

Figure 3. Errors of the scientific method.

from conclusions. A "heritage" [23] of important results is supported by proofs newly written in the current idiom. Examples of renewal are the volumes of Bourbaki [24] and the history of "Rolle's theorem" [25], which began with a critic of infinitesimals and now is basic to real analysis.

In contrast to the multiple sources for scientific knowledge, proofs are a single point of failure for core mathematics. Mistakes are difficult to find because mathematical arguments are abbreviated in two ways: ${ }^{6}$ (A) "Splicing" inserts results that were established in earlier work. Mistakes are likely to be caught only when an article receives close scrutiny upon being "spliced" into other articles. Scrutiny can take years, as evidenced by the low citation-impact factors for mathematics journals. (B) "Skipping" leaves out parts of arguments, perhaps inadvertently or to save space. Davis [26] identifies two other reasons for "skipping": boredom ("you cannot expect me to do every step") and superiority ("this step is easy for a happy few"). The ambiguity in what constitutes a complete proof contributed to a brouhaha over the resolution of Henri Poincaré's conjecture [29]. "Skippers”, rather than being cavalier, may be highly functioning researchers:

... he is like a clairvoyant to whom truths appear in a bright light, but mostly to him alone. $^{7}$

$$
\text { - Charles Hermite [30, p. 147] }
$$
on his student Poincaré

\footnotetext{
${ }^{6}$ This discussion follows Davis [26]. The rhetoric of proof is examined in [27], [28].

7 “Souvent Picard lui a demandé, sur des points d'une grande importance dans ses articles des Comptes Rendus, des éclaircissements et des explications, sans pouvoir jamais rien obtenir qu'une affirmation: 'c'est ainsi, c'est comme cela', de sorte qu'il semble comme un voyant auquel apparaissent les vérités dans une vive lumière, mais en grande partie pour lui seulement."
} 


\section{Low Tolerance for Corrections}

Comparatively little is known about the innate talents of mathematicians [31]. Reid [32, pp. 66-67] contrasts the abilities of Bernhard Riemann and David Hilbert by arguing that creating new mathematics is different from devising the formalist proofs which Hilbert made standard. It follows that writing proofs may use some talents found in the general population.

"Perfectionism" is a personality construct explained as striving for flawlessness and setting high personal standards. ${ }^{8}$ Perfectionists share characteristic tendencies, including a low tolerance for mistakes and a preference for order [33]. Perfectionism has both adaptive and maladaptive components: high standards coupled with organizational skills contribute to achievement, whereas concern about making mistakes coupled with self-criticism creates anxiety and depression. To avoid the negative personality consequences, it suffices that perfectionists need only to avoid learning of their failings (see Figure 4). Denying mistakes or trivializing their impact are defenses that can be observed in mathematicians. ${ }^{9}$

Anecdotal evidence supports the explanation that the social mores of mathematicians discourage publishing corrections. Lecat [36] recorded hundreds of mistakes in nineteenth-century publications. Pertinent is that the authors did not find and report these errors. In a subject whose primary research methodology is logic, there is little advantage to admit making mistakes. When Poincaré found a severe error in his prize-winning essay on dynamics, the chairman of the prize committee, Gösta Mittag-Leffler, employed subterfuge to retrieve the few printed copies of the essay that had been distributed, including to committee member Karl Weierstrass. Mittag-Leffler instructed Poincaré to acknowledge only that the essay had been revised so as to avoid disclosing the failure of the committee [37, p. 67]. Attention is drawn to errors in proportion to the stature of the person who corrects them, so correcting may be regarded as unsuitable work for senior mathematicians. Olga Taussky [38, pp. 18-19] relates that David Hilbert's collected works were "edited" by very talented and very junior temporary workers. "Hilbert's work was not free from error of all magnitudes...We worked very hard on all this, but later even more errors emerged."

Like the editorial changes to Hilbert's work, mathematicians are open to corrections made

\footnotetext{
${ }^{8}$ Frost et al. [33] introduced the multidimensional view of perfectionism. This discussion summarizes the survey of Tofaha and Ramón [34].

${ }^{9}$ The reluctance of authors and editors to acknowledge the need to publish a correction can be appreciated perhaps only through experiences such as chronicled by Hill [35].
}

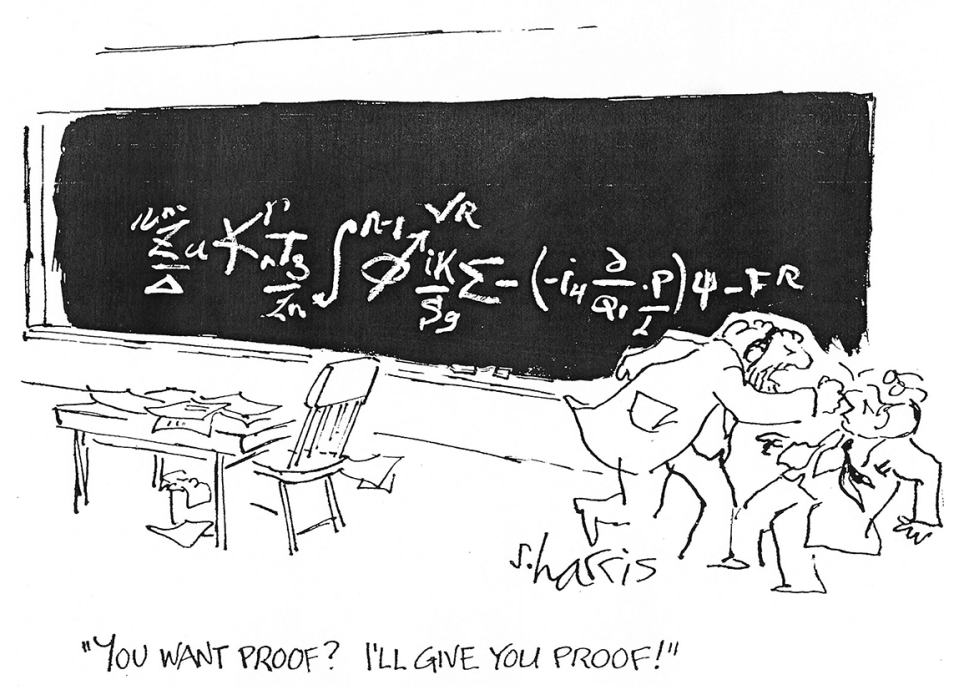

Figure 4. Woe to the finder of errors.

covertly. Corrections may be embedded in other articles rather than in explicit (1) errata or (2) comments. These corrections by their nature are difficult to identify (see Table 3 ). The relative quantities found by one method suggest that unannounced corrections are more common in mathematics than in other fields.

Table 3. Documents with embedded corrections as gleaned from abstracts. Percent of all journal documents in Scopus subject areas for 19902010.

\begin{tabular}{|l|c|}
\hline \multicolumn{1}{|c|}{ Subject Area } & $\%$ \\
\hline \hline Mathematics & 0.017 \\
Computer Science & 0.012 \\
Earth ... Science & 0.009 \\
Decision Sciences & 0.008 \\
Econ. and Finance & 0.008 \\
Physics & 0.006 \\
Engineering & 0.004 \\
All Subjects & 0.002 \\
\hline
\end{tabular}

The reluctance to discuss corrections is further manifest in a high tolerance for unacknowledged errors: ${ }^{10}$ "There are a number of gray areas in which the experts know that the proofs are not complete or are partly incorrect. Since they are experts they know exactly what you can take; in a sense they are the happy few. This situation is definitely not acceptable, and we have to fight that results are really available (and not by jumping over this statement, which is not true, but you can take the next one, and so on). In recent years, for many reasons [competition, complexity, and proliferating duties which reduce the time for

\footnotetext{
${ }^{10}$ The quoted material is paraphrased for readability from a presentation of Bourguignon [39].
} 
careful peer review], the gray areas have been growing, and if they reach a certain level, then mathematical development will be injured."

The most minute errors are not in mathematical matters to be scorned. ${ }^{11}$

$$
\begin{array}{r}
\text { - Isaac Newton [40, pp. 124-125] } \\
\text { referring to fluxions }
\end{array}
$$

\section{No Editorial Guidance}

The editorial practices of journals mirror the research methods of their fields. In the sciences, as noted [9], [10], students learn to be vigilant for experimental errors (human, random, systematic) and for errors in theories (called "models" to highlight the approximate nature). Sensitization to errors continues throughout scientific careers. The Council of Science Editors expressly states, "The editor's concern should be correcting the literature so the readership can rely on the information published"; biomedical and multidisciplinary journals are recognized for exemplary corrective policies $[41$, pp. 62,57$]$. These practices ensure that the scientific literature improves continuously, like science itself.

Mathematicians take an axiomatic approach. Just as Platonic mathematics has no errors by definition, articles emerging from peer review should be free of error in principle. The editorial guidelines of the AMS [42] and the IMU [43] do not consider amending the literature-they are guidelines for an ideal world. ${ }^{12}$ Gray areas are not mistakes by this view but rather are lacunae that would be filled if only the reviewers would be thorough. Such faith in an ideal process is inconsistent with its implementation. Editors note that reviewers can only be "reasonably certain" about the correctness of articles [45], [46]. Compounding the drawbacks of relying on peer review for correctness, editorial decisions in mathematics are typically based on a single review [47], whereas in many fields the custom is two or three reviews, and the process may be double-blind in social sciences [48]. ${ }^{13}$

The lack of editorial policies inviting correction goes hand in hand with low rates of corrections in mathematics journals. Mathematics societies publish vanishingly few corrections in their journals compared to medical and scientific societies and fewer than even engineering societies (see

\footnotetext{
11 "Errores quàm minimi in rebus mathematicis non sunt contemnendi."

${ }^{12}$ Ethical guidelines urge individuals to correct errors [44], but where to publish corrections is moot. Some journals privately advise authors to post corrections on their personal websites, which is not consistent with the concept of an archival literature.

${ }^{13}$ Anonymity strengthens the integrity of the review process in that articles with gray areas are less likely to be accepted because a happy few authors are well known to reviewers.
}

Table 4). The mathematics subject areas with high rates of (2) comments from readers are all interdisciplinary fields (see Figure 5). Subjects 81 and 83 are heavily published by the Institute of Physics ${ }^{14}$ which invites reader comments in all its journals. Subject 93 is the rare, very large branch of mathematics that publishes comments in theoretical (i.e., mathematical) journals such as Automatica.

Table 4. Some prominent individual journals (top) and all the journals of some professional societies (bottom) ranked by corrections (1-3) as percent of documents for 1990-2010. Data from Scopus except from Zentralblatt (*) for mathematics. "IF" is the Institute for Scientific Information 2-year citation impact factor for

\begin{tabular}{|c|c|c|c|c|}
\hline \multirow[b]{2}{*}{ Publications } & \multicolumn{3}{|c|}{ Percent } & \\
\hline & 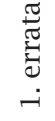 & 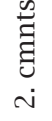 & $\begin{array}{l}\dot{\Xi} \\
\dot{\Xi} \\
\dot{0}\end{array}$ & IF \\
\hline New Eng. J. Med. & 3.6 & 5.3 & 0.1 & 53 \\
\hline$J . A M A$ & 3.1 & 3.4 & 0.3 & 30 \\
\hline AAAS Science & 3.9 & 0.5 & 0.2 & 31 \\
\hline Lancet & 2.5 & 1.1 & 0.1 & 34 \\
\hline Nature & 2.0 & 0.2 & 0.3 & 36 \\
\hline All subject areas & 0.6 & 0.4 & 0.3 & \\
\hline All mathematics & 0.6 & 0.2 & 0.4 & \\
\hline IEEE journals & 0.4 & 0.4 & 0.4 & \\
\hline ASME journals & 0.4 & 0.1 & 0.4 & \\
\hline AMS journals* & 0.2 & 0.0 & 0.5 & \\
\hline All mathematics* & 0.2 & 0.1 & 0.2 & \\
\hline SIAM journals* & 0.2 & 0.1 & 0.2 & \\
\hline
\end{tabular}
2010 , rounded to whole numbers.

\section{It Takes a Community}

In summary, the mathematics literature observably has low correction rates, yet systemic considerations suggest that mathematicians do not have lower error rates than other researchers. This mismatch may stem from a cultural emphasis on perfection that discourages discussing mistakes. The consequences are an absurdly high expectation for peer review to catch all errors and a neglect of policies to correct the literature once published.

One might see publication practices in mathematics as especially defective, but that would be unfair to many other fields; see the hilarious [49]. The onus is on mathematics societies, which have not led in addressing shortcomings in their publication processes, thereby leaving editors to fret over

\footnotetext{
${ }^{14}$ See Journal of Physics A: Mathematical and Theoretical and Classical and Quantum Gravity. The single journal with most articles indexed by Zentralblatt for the decade 2000-2009 is J. Phys. A.
} 
the difficulty of finding "good" (i.e., superhuman) reviewers.

A reasonable approach is to emulate the large scientific and medical journals, whose editorial policies welcome reader participation. Journals should be community forums in which new results evolve:

1. For example, authors might prefer a streamlined editorial process that solicits multiple reviews of limited duration. Editors should not expect to publish papers with the same level of refinement as Bourbaki's encyclopedia. Indeed, results become refined through discussion.

2. The criteria for acceptance could be broadened from the significance of new results to corroborating recent results or to introducing innovative proofs. The most important contributions of some articles are the methods rather than the conclusions, but methods are seldom explicitly discussed and are not presently a criterion for publication [39].

3. Perhaps it should be emphasized that the single point of failure of publishing results only once could be addressed by inviting corroborating papers with alternate proofs. In the sciences, conclusions are not accepted until duplicated by independent studies [50].

4. Finally, journals should invite reader assistance to clarify published results by establishing guidelines for comments, accelerating review, and stating criteria for acceptance. (Because editors share responsibility for errors, they should not have complete discretion in publishing corrections.) Such practices would elevate instead of stigmatize corrections to the literature.

Rather than rail at citation impact factors, mathematics editors can be proactive to attain high impact through reader involvement, just as the editors of Lancet and Nature do (see Table 4). It should not be lost on publishers that articles in a journal that operates as a forum are more likely to be cited, and quickly.

\section{Appendix: Scopus and Zentralblatt Data}

Scopus [2] classifies documents by source and type. In Figure 2 and Table 4:

1. "Errata" are documents of type "er" (errata, which in Scopus includes republications and retractions). Searching titles for "addend*", "correction" to", "corrigend*", or "errat*" finds some errata missing from the "er" class. The asterisk matches any full word.
Percent Corrections in Mathematics Subjects 1990-2010

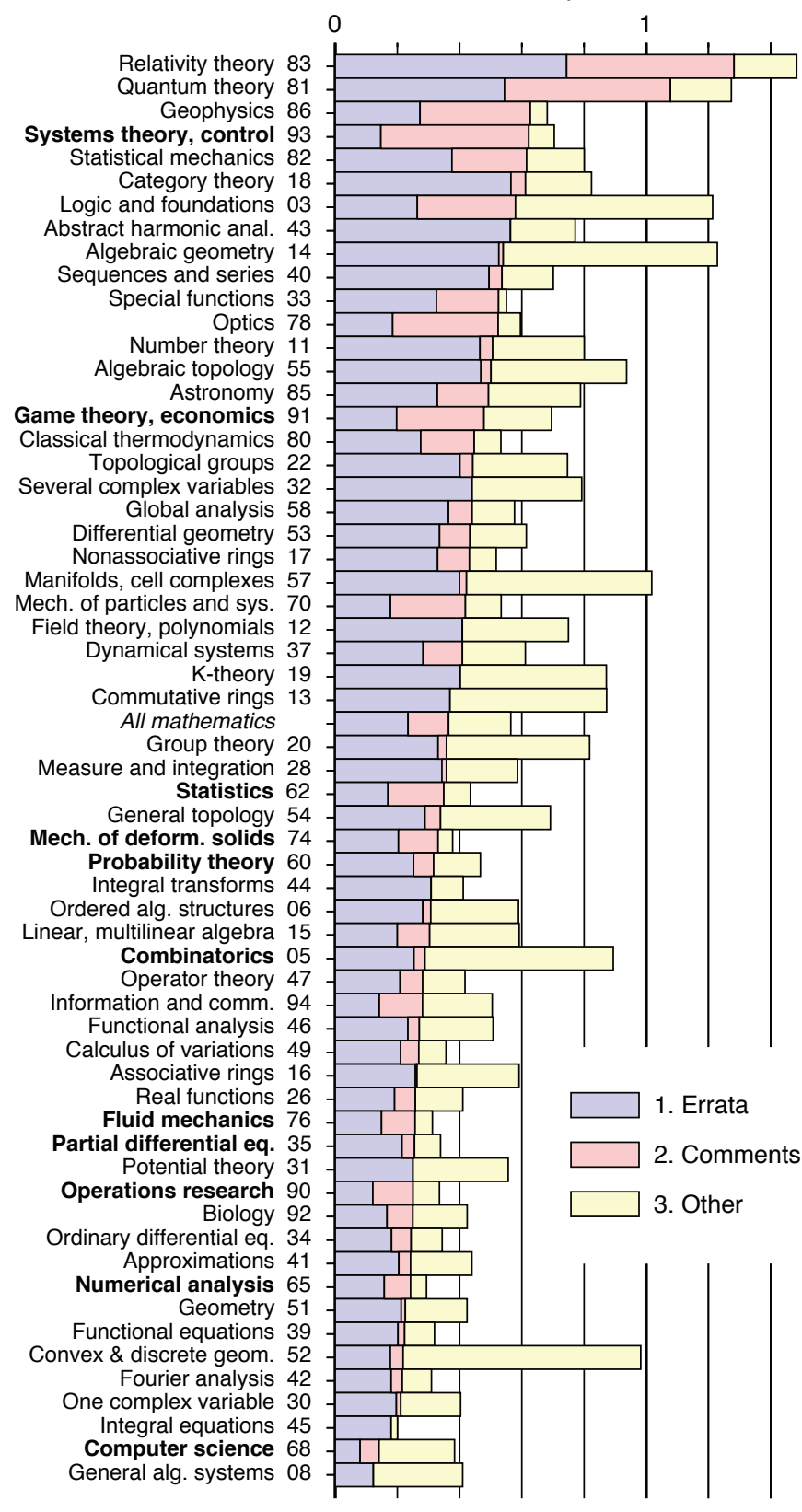

Figure 5. Error rates as percent of articles in the primary Mathematics Subject Classifications [7] from Zentralblatt [8]. The eleven subjects in bold contribute 51 percent of publications.

2. "Comments" are documents whose titles contain "comment* on", "replies", "reply", or "response to comment*", except "comment" may not be preceded by "and", "for", "some", or "with". Comments are undercounted for journals that identify them with only the distinguishing keyword "letter". Letters are omitted because they may also be short research articles or opinion pieces. 
3. "Other" corrections have titles, abstracts, or keywords containing "contradict(s)", "counterexample to", "disproves(s)", "inconsistent", "invalidate(s)", or "refute(s)".

The overlap among the three groups is 0.33 percent, and 97 percent have source type "j" (journal), so percentages are with respect to all " $\mathrm{j}$ " documents. The percentages may underestimate corrected articles, because only 85 percent of "j" documents are of type "ar" (article) or "cp" (conference paper). The balance are reviews, short articles, editorials, errata, and letters. This other content is numerous for the five specific journals in Table 4, but for consistency the percentages remain with respect to all content, thus underestimating the percent of corrections to substantive articles. In Table 3, stealth corrections are documents whose abstracts contain "we (also) correct" (not preceded by "after", "if", or "when", and not succeeded by "for") and which are not already identified as (1) errata or (2) comments.

The source for Figure 5 is Zentralblatt MATH [8]. Corrections are found as for Scopus, except only titles are searched for (1) errata, and (3) other omits "inconsistent", which appears with a technical meaning in subject class 03 logic. The overlap among the three groups of errors (1-3) is 0.8 percent. Documents of type "j" (journal article) have 92 percent of these documents, while type "a" (book article) have 7 percent. In Figure 5 the percentages are relative to all "a" or "j" documents for the leading two digits of the primary mathematics subject class.

There are considerable differences in coverage between the two databases. Zentralblatt specializes in mathematics and finds roughly double the number of mathematics articles for 1990-2010. Because Scopus classifies journals by subject area, it indexes as mathematics some articles which are not mathematical.

\section{Acknowledgments}

I thank the reviewers for interesting comments and the editor for assembling the panel. Their handiwork is clear, if only to themselves.

\section{References}

[1] G. NAIK, Mistakes in scientific studies surge, The Wall Street Journal CCLVIII(34):A1, A12, Aug. 10, 2011.

[2] Elsevier, SciVerse Scopus, website, 2011.

[3] I. Newton, Philosophiae Naturalis Principia Mathematica (Mathematical Principles of Natural Science), William and John Innys, London, 3rd edition, 1726.

[4] J. HenRY, "Mathematics made no contribution to the public weal": Why Jean Fernel (1497-1558) became a physician, Centaurus 53(3):193-220, 2011.

[5] S. M. STIGLER, The History of Statistics: The Measurement of Uncertainty before 1900, Harvard University Press, Cambridge, MA, 1986.
[6] J. F. GRCAR, John von Neumann's analysis of Gaussian elimination and the origins of modern numerical analysis, SIAM Rev. 53(4):607-682, 2011.

[7] Amer. Math. Soc. 2010 Mathematics Subject Classification, website, 2010.

[8] FIZ Karlsruhe, Zentralblatt MATH-Serials Database, website, 2011.

[9] H. BASsow, Interdependency and the importance of errors in chemistry, J. Chem. Educ. 68(4):273-274, 1991.

[10] C. J. GIUNTA, Using history to teach scientific method: The role of errors, J. Chem. Educ. 78(5):623-627, 2001.

[11] T. S. KuHN, The Structure of Scientific Revolutions, University of Chicago Press, Chicago, 2nd edition, 1970.

[12] A. GELFERT, Mathematical rigor in physics: Putting exact results in their place, Philos. Sci. 72(5):723-738, 2005.

[13] S. E. Toulmin, Return to Reason, Harvard Univ. Press, Cambridge, MA, 2001.

[14] K. DAVEY, Is mathematical rigor necessary in physics? Brit. J. Philos. Sci. 54(3):439-463, 2003.

[15] F. QUINN, A revolution in mathematics? What really happened a century ago and why it matters today, Notices Amer. Math. Soc. 59(1):31-37, 2012.

[16] W. G. VincENTI and D. BLOOR, Boundaries, contingencies and rigor: Thoughts on mathematics prompted by a case study in transonic aerodynamics, Soc. Stud. Sci. 33(4):469-507, 2003.

[17] L. Adelman, P. E. Lehner, B. A. Cheikes, and M. F. TAYLOR, An empirical evaluation of structured argumentation using the Toulmin argument formalism, IEEE T. Syst. Man Cyb. 37(3):340-347, 2007.

[18] J. F. GRCAR, Mathematics turned inside out: The intensive faculty versus the extensive faculty, Higher Education 61(6):693-720, 2011.

[19] M. AтIYAH et al., Responses to "Theoretical mathematics”, Bull. Amer. Math. Soc. (N.S.) 30 (2):178-207, 1994.

[20] D. H. BAILEY and J. M. BoRWEIN, Exploratory experimentation and computation, Notices Amer. Math. Soc. 58 (10):1410-1419, 2011.

[21] J. GRABINER, Is mathematical truth time-dependent? Amer. Math. Monthly 81 (4):354-365, 1974.

[22] J. VON NEUMANN, The mathematician, in R. B. Heywood, editor, The Works of the Mind, Univ. of Chicago Press, Chicago, IL, 1947, pp. 180-196.

[23] I. GRATTAN-GuINNESS, The mathematics of the past: Distinguishing its history from our heritage, Historia Math. 31 (2):163-185, 2004.

[24] J. Dieudonné, The work of Nicolas Bourbaki, Amer. Math. Monthly 77:134-145, 1970.

[25] J. BARROW-GREEN, From cascades to calculus: Rolle's theorem, in E. Robson and J. A. Stedall, editors, The Oxford Handbook of the History of Mathematics, Oxford University Press, Oxford, UK, 2009, pp. 737-754.

[26] P. J. DAvis, Fidelity in mathematical discourse: Is one and one really two? Amer. Math. Monthly 79 (3): 252-263, 1972.

[27] A. ABERDEIn, Mathematics and argumentation, Found. Sci. 14(1-2):1-8, 2009.

[28] A. Pease, A. Smaill, S. Colton, and J. Lee, Bridging the gap between argumentation theory and the philosophy of mathematics, Found. Sci. 14 (1-2):111-135, 2009. 
[29] S. NASAR and D. Gruber, Manifold destiny, New Yorker, August 28, 2006.

[30] C. HeRMitE, Lettres de Charles Hermite à Gösta MittagLeffler (1884-1891), Cahiers du séminaire d'histoire des mathématiques 6:79-217, 1985.

[31] M. ATIYAH, Thoughts of a mathematician (book review), Brain 131 (4):1156-1160, 2008.

[32] C. REID, Hilbert, Springer-Verlag, Berlin,1970.

[33] R. O. Frost, P. MARTEN, C. LAHART, and R. RosenBLATE, The dimensions of perfectionism, Cognitive Ther. Res. 14 (5):449-468, 1990.

[34] G. A. S. TOFAHA and P. R. RAMÓN, Perfectionism and self concept among primary school children in Egypt, Electronic Journal of Research in Educational Psychology 8 (3):1099-1114, 2010.

[35] T. HILL, Hoisting the black flag (letter), Notices Amer. Math. Soc. 57 (1):7, 2010.

[36] M. LECAT, Erreurs de mathématiciens des origines à nos jours, Castaigne, Brussels, 1935.

[37] J. BARRow-GreEn, Poincaré and the three body problem, Amer. Math. Soc., Providence, RI, 1997.

[38] M. Terrall, editor, Olga Taussky-Todd (1906-1995) Autobiography, California Institute of Technology Archives, Pasadena, CA, 1980.

[39] J.-P. BouRGuignON, The role of publications in mathematical research: A systemic point of view, MSRI Workshop on Mathematics Journals, web video, 2011.

[40] I. NEWTON and D. T. WHITESIDE, The Mathematical Papers of Isaac Newton: 1697-1722, volume 8 of The Mathematical Papers of Sir Isaac Newton, Cambridge Univ. Press, Cambridge, UK, 2008.

[41] D. SCOTT-LICHTER, editor, CSE's White Paper on Promoting Integrity in Scientific Journal Publications, Council of Science Editors, Editorial Policy Committee, Wheat Ridge, CO, 2009.

[42] Amer. Math. Soc., Manual for Journal Editors, web document, 2011.

[43] International Math. Union, Best Current Practices for Journals, web document, 2010.

[44] Amer. Math. Soc., Ethical Guidelines, web document, 2005.

[45] A. J. Hildebrand, Getting Published in Mathematics, Univ. of Illinois web document, 2009.

[46] P. R. Halmos, I Want to Be a Mathematician, SpringerVerlag, New York, 1985.

[47] S. G. Krantz, How to write your first paper, Notices Amer. Math. Soc. 54 (11):1507-1511, 2007.

[48] A. R. Young, Publishing research articles, in A. R. Young, J. Duckett, and P. Graham, editors, Publishing in Politics, Political Studies Association, 2nd edition, 2010.

[49] D. TRAFImOW and S. Rice, What if social scientists had reviewed great scientific works of the past? Perspect. Psychol. Sci. 4 (1):65-78, 2009.

[50] G. NAIK, Scientists' elusive goal: Reproducing study results, The Wall Street Journal CCLVIII (130):A1, A16, Dec. 2, 2011.

Editor's Note: Credit for Figures 1, 3, and 4 is ScienceCartoonsPlus. com.

\section{About the Cover Visualizing the impact of humans on the planet}

April is Mathematics Awareness Month, and this year's theme is the application of mathematics to problems of sustainable development. One of the most interesting ways in which mathematics comes into this is in the processes by which one keeps track of the success or failure of attempts at sustainability. The most impressive projects of this kind these days are carried out from space, and largely through the National Aeronautics and Space Administration (NASA).

The cover image has been taken from the NASA web page

http: //earthobservatory.nasa.gov/ Features/NightLights/page2.php

and shows dramatically how civilization has extended itself over the western hemipshere. Some background on the technology behind the night-time images can be found at

http://www.ngdc.noaa.gov/dmsp/data/viirs_ fire/viirs_html/viirs_ntl.html

The hundreds of photographs that can be found from links on these pages are an amazing resource.

A more detailed analysis of the effect of human development on the Earth can be found by searching the NASA site for "human footprint"-perhaps coming up with the following map:

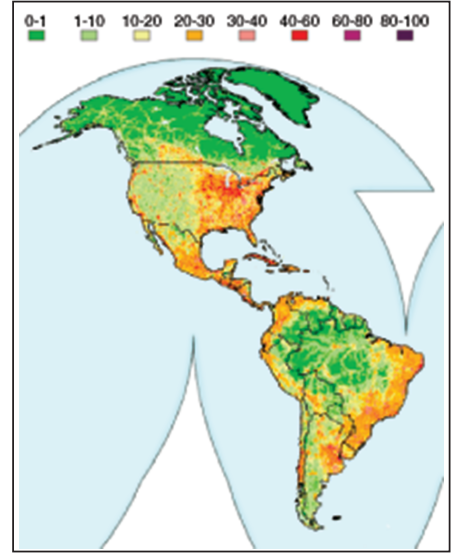

Each individual biome is rated on its own scale 0-100, with maximum 100. (This is cropped from the original.)

The night lights images are the output of a massive quantity of data transmitted by satellites, which is then massaged for the Earth Observatory website by the data visualization group at the Goddard Space Center. We thank the group's manager, Robert Simmon, for spending valuable time answering our questions.

Tracking all the ways in which mathematics is applied to produce these images could be a valuable exercise.

-Bill Casselman, Graphics Editor (notices-covers@ams.org) 